\title{
Incidentally Diagnosed Case of Molluscum Contagiosum of Cervix
}

NIKUNJA LATA DUTTA' 1 , BANASMITA BARUAH², PRANJAL KUMAR GOGOI ${ }^{3}$

\section{ABSTRACT}

Molluscum Contagiosum (MC) is a common viral Infection of Skin caused by Double Stranded DNA virus that is Pox Virus group effecting mainly humans. It effects mainly school going children, adults and immuno suppressed individuals. e.g., HIV infection, women with dialysis, oral contraceptive, HPV infection, nutritional factors (poor nutrition). In children the most common site of infection of MC are skin of face, trunk and extremities where as, in Adults, genitals are commonly affected and rarely palms, sole and mucus membrane are also involved. The infection in genitals is lowest about $3 \%$. In this context a case of incidentally diagnosed $\mathrm{MC}$ of cervix is presented here. The cervical infection of $\mathrm{MC}$ is very rare. Till date probably only two cases have been reported in the medical literature.

\section{CASE REPORT}

A 76-year-old female attending a Gynaecology Out Patient Department clinic complaining of post-menopausal bleeding since last two weeks and no such relevant past medical history regarding pre disposing factor like use of drugs, oral contraceptives and dermatological conditions like eczema or atopic dermatitis and dialysis, for MC infection was noted with poor environmental condition and poor nutrition. There was no such definite immunocompromised status found except poor environment using a common pond or lake for bathing and washing clothes and utensils. The infection may occur from linens such as clothing, towel and bathing sponges [1]. On local examination foul smelling blood stained white discharge was noted. Per Vaginal examination revealed a small nodular feeling in the posterior lips of the cervix. On per speculum examination of the cervix reddish nodule with thick white discharge over it was observed. The swelling was non symptomatic except vaginal bleeding. A provisional clinical diagnosis of infective lesion or any other tumorous lesion was made. Duration of lesion was not known. Patient reported after two weeks of vaginal bleeding. To confirm the diagnosis biopsy was taken and formalin fixed tissue sample was sent for histopathological examination. Physical examination of patient does not show any lesion elsewhere in the body and no systemic disorder could evaluate except very poor nutritional status at the time.

Grossly, a small grey white soft tissue mass about $0.5 \mathrm{~mm}$ length, 0.4 $\mathrm{mm}$ in thickness and $0.5 \mathrm{~mm}$ in breadth. Macroscopic photography was not taken because of photographic inconvenience.

Microscopic examination of haematoxylin and eosin stain of tissue block sections showed moderate hyperplasia of stratified squamous epithelium and cup shaped changes [Table/Fig-1]. Intact basal layer of cells. Above the basal layer keratinocytes with variable sized eosinophilic bodies [Table/Fig-2]. Above this zone MC bodies push the nucleus towards the periphery with a thin rilm of cytoplasm. The surrounding tissues show necrosis and acute inflammatory cells (neutrophil) reaction. [Table/Fig-3] shows the evidences polymorphs with variable sized molluscum bodies. With this classic histological picture and clinical findings, diagnosis of Molluscum Contagiosum of cervix was given.

\section{DISCUSSION}

Molluscum Contagiosum is a common self-limiting viral infection of skin with single discrete or multiple papular or nodular lesions. $\mathrm{MC}$ virus belongs to pox virus family having a dumbbell shaped
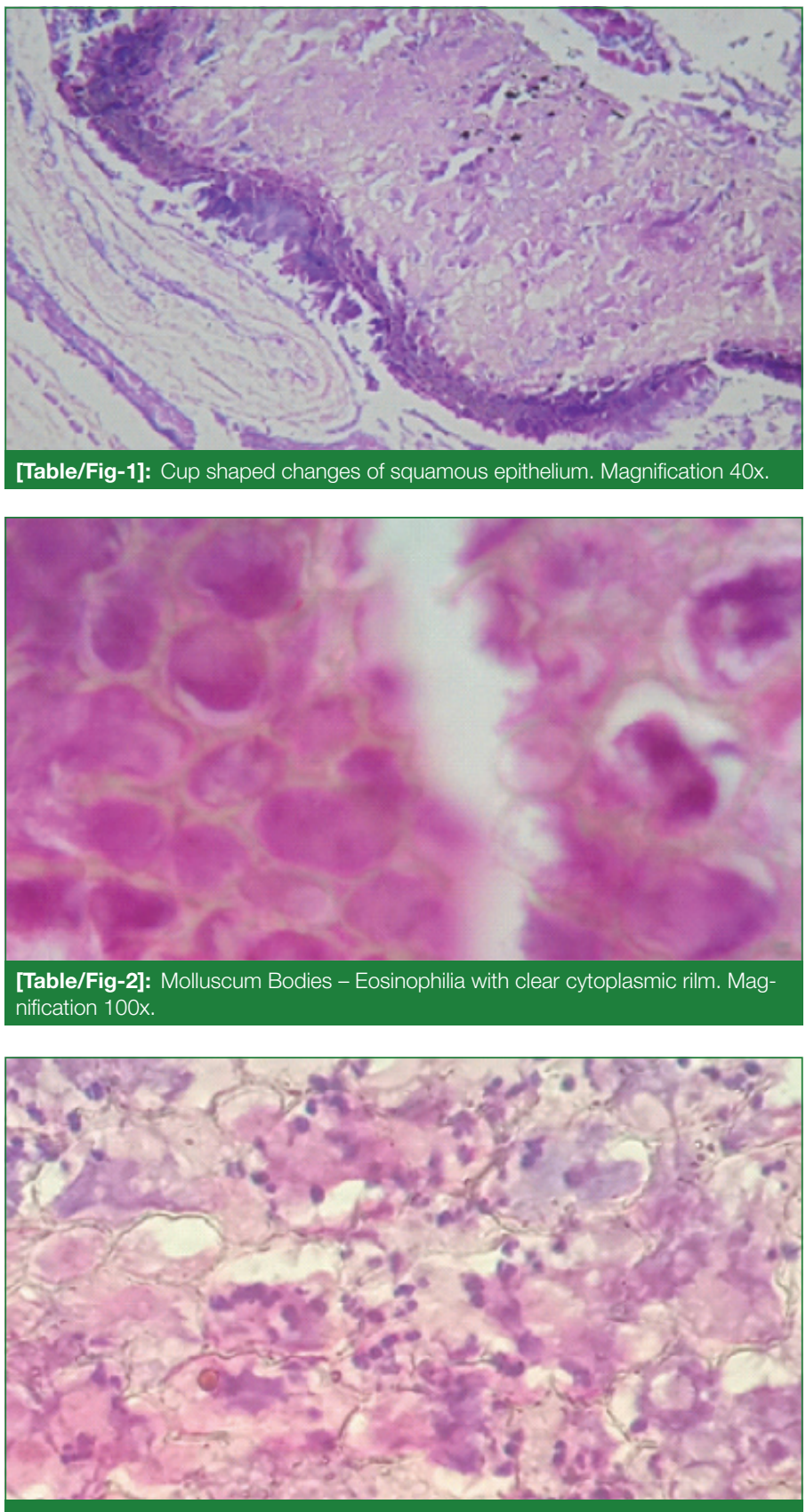

[Table/Fig-3]: Polymorphs with variable sized Molluscum Bodies. Magnification 100x. 
DNA core which represents the largest pathogenic pox virus in human and largest virus in nature. The Molluscum Contagiosum virus was first described by Sir Bateman in the year 1817 [2]. MC is of four types MCV I, MCV II, MCV III, MCV IV of which MCV I is most prevalent and MCV II is usually seen in adults. MC is common in children in ages 1-12 years, sexually active adults, immuno compromised hosts such as those with HIV infection, concurrent dermatology conditions such as eczema or atopic dermatitis in women with dialysis, HPV infection and use of oral contraceptives or poor environment and poor nutritional factors [1]. MC Virus infection transmitted via either direct contact or with infected people or indirectly through infected fomites like towel, sponges, swimming pools and tattoo instruments. It also spreads via sexual contact or by auto inoculation. The incubation period of $\mathrm{MC}$ virus varies from 2-8 weeks and some extend up to 6-18 months. In children MC lesion frequently involve skin of face, neck, wrist, arms, hands and mucus membrane of lips, tongue and buccal mucosa. In sexually active adults and those with immune suppressive states the lesion involves genitals, abdomen and other inner part of thigh. The lesions are usually self-limiting whereas immuno compromised persons suffering from extensive disease process with disfigurement. The incident of $\mathrm{MC}$ virus is $2-10 \%$ in world population. Occurrence of $\mathrm{MC}$ Virus in genital area is lowest approximately $3 \%$ [3]

Molluscum Contagiosum of the cervix is very rare probably till date two cases have been reported in English scientific literature $[3,4]$. This case was an incidentally diagnosed case. The risk factors are probably poor environment with poor economic status and poor nutrition, post-menopausal bleeding probably with low immunity. Clinically the lesion of Molluscum Contagiosum appears as firm flesh coloured doughnut or umbilical shaped lesions ranges from 2-5 mm. Sometimes with eczematous lesion increases in size about $10 \mathrm{~mm}$. It begins as a small painless papule or an erythematous base which is later on raise to a pearly white dome shaped nodule with a central depression like an umbilication characteristically referred to a mollusca. The central pit may contain waxy or cheesy material containing the virions [5]. In this present case the lesion present as firm nodule with reddish white discharge around. Diagnosis of lesion is presumptively based on distinct clinical appearance and histomorphological features on light microscopy which are very classical. Hence other molecular investigations are not done. Histological sections reveal a spectrum of cup shaped verrucous epidermal hyperplasia. The lesions contain numerous diagnostic eosinophilic or bluish purple Molluscum Bodies or Henderson Paterson Bodies which are spherical aggregates of viral particles in the cells of Stratum Granulosum and the Stratum
Corneum. The hyperplastic epidermis shows acanthosis and basal layer shows enlarged basophilic nuclei and mitotic figures. The intra cytoplasmic inclusions were first described by Henderson Patterson in the year 1841 [6]. Usually dermis is relatively unremarkable but when the contents of the lesions are discharged into it, the dermis shows intense inflammatory cell reactions composed of neutrophil lymphocyte histiocytes, an occasional foreign body giant cell. Sometimes inflammatory reaction presents as an abscess and sometimes in the form of a pleomorphic T-Cell infiltrate that can simulate a lymphomas/leukemic process [4]. In our case the histomorphological features of the cervical biopsy specimens were classical.

Molluscum Contagiosum is a benign self-limiting process usually undergoes spontaneous resolution within months. Virus in the later stages is considered as a non-self by our body leading to activation of inflammatory process and causing spontaneous remission of this infection. But cases associated with HIV infection or atopic Dermatitis may have an extensive and severe course because of immune suppression [4]. Usually supportive treatment suffices and it is in the form of curettage, laser cryo-therapy using liquid nitrogen or application Salicylic Acid [4]. The infection may complicate ending in secondary infection or cellulitis. Healthy patient experience a good prognosis. The present case underwent biopsy but did not comply with follow up treatment.

\section{CONCLUSION}

Molluscum Contagiosum of Cervix is very rare. It can be only an incidental finding in a host with very poor economic status with poor environment and poor nutrition probably with low immunity.

\section{REFERENCES}

[1] Centre for Disease Control and Prevention, National Centre for Emerging and Zoonotic Infectious Diseases (NCEZID), Division of High-Consequence pathogens and Pathology (DHCPP). (https://www.cdc.gov/ncezid/dhcpp/index. html)

[2] Bateman F. Molluscum contagiosum. In: Shelley WB, Crissey JT, eds. Classics in Dermatology. Springfield IL; Charles C Thomas, 1953, p20.

[3] Bagel A, Raju K, Munisamaiah M, Raghavendra Prasad BN. Molluscum contagiosum of cervix- A case report. J Clin Diagn Res. 2017;11(1):ED03-ED04. doi:10.7860/JCDR/2017/24545.9186

[4] Lang TU, Mochelow P, Khalbuss WE, Monaco SE, Ponntonowitz L. Molluscum Contagiosum of the cervix. Diagn Cytopathol. 2012;40(7):615-16.

[5] Nandhini G, Rajkumar K, Kanth KS, Nataraj P, Ananthakrishnan P, Arunachalam M. Molluscum contagiosum in a 12-year-old child - report of a case and review of literature. J Int Oral Health. 2015;7(1):63-66.

[6] Brown ST, Nalley JF, Kraus SJ. Molluscum contagiosum. Sex Transmit Diseases. 1981;8:227-34.

PARTICULARS OF CONTRIBUTORS:

1. Retired Professor, Department of Pathology, Assam Medical College, Dibrugarh, Assam, India.

2. Pathologist, Department of Pathology, Aditya Hospital, Dibrugarh, Assam, India.

3. Demonstrator, Department of Pathology, Assam Medical College, Dibrugarh, Assam, India.

NAME, ADDRESS, E-MAIL ID OF THE CORRESPONDING AUTHOR:

Dr. Nikunja Lata Dutta,

Banipur by Lane 5 B, Near New Dibrugarh Railway Station, Dibrugarh-786003, Assam, India.

E-mail: avi.forever.after@gmail.com

Date of Submission: Nov 18, 2018 Date of Peer Review: Dec 25, 2018

Date of Acceptance: Jul 17, 2019

Date of Publishing: Oct 01, 2019

FINANCIAL OR OTHER COMPETING INTERESTS: None. 